\title{
Insight into the noble crayfish morphological diversity: a geometric morphometric approach
}

\author{
Leona Lovrenčić ${ }^{1}$, Humberto G. Ferrón ${ }^{2}$ (D), Dorotea Grbin $^{3}$ and Ivana Maguire ${ }^{1, *}$ (D) \\ ${ }^{1}$ University of Zagreb, Faculty of Science, Department of Biology, Zagreb, Croatia \\ ${ }^{2}$ University of Valencia, Cavanilles Institute of Biodiversity and Evolutionary Biology, Valencia, Spain \\ ${ }^{3}$ University of Zagreb, Faculty of Food Technology and Biotechnology, Zagreb, Croatia
}

Received: 21 September 2021 / Accepted: Accepted: 2 February 2022

\begin{abstract}
The noble crayfish (Astacus astacus), a keystone species of high ecological, economic, and cultural importance in Europe, is threatened due to a long-term population decline caused by anthropogenic pressure on its habitats, the presence of non-indigenous invasive crayfish species and climate change. Since the effective protection of the remaining populations requires conservation measures based on the comprehensive knowledge of the species, including good understanding of its genetic and morphological variability, our aim was to study morphological features of the noble crayfish in Croatia using geometric morphometrics for the first time. We applied two-dimensional geometric morphometrics to find morphological differences among 15 populations of the noble crayfish from Croatian freshwater habitats, grouped according to previously established (a) mitochondrial (genetic) lineages, (b) genetic clusters inferred from nuclear microsatellites, as well as (c) river basins and (d) habitat types (lotic, lentic). Overall, the results indicated the existence of morphological diversity among the studied populations of the noble crayfish in Croatia. Shape analysis showed differences in cephalon based on crayfish affiliation to different genetic lineages, genetic clusters, river basins and habitat types. Our study provided novel insights into morphological diversity of the endangered noble crayfish in the area of its high genetic diversity.
\end{abstract}

Keywords: Astacus astacus / freshwater crayfish / biodiversity / landmarks / shape analysis

\section{Introduction}

Freshwater ecosystems in the Mediterranean Basin are considered one of the global biodiversity hotspots (Myers et al., 2000). Concurrently, they are among the most endangered habitats and their biodiversity is declining dramatically, with high extinction rates and copious amount of threatened species (Dudgeon et al., 2006; Strayer and Dudgeon, 2010; Collen et al., 2014). One of Mediterranean countries is Croatia, located in the south-eastern Europe, on the dividing line between four biogeographical regions. Due to its outstandingly diverse ecological, climatic, and geomorphologic features, alongside complex paleo-hydrogeology, Croatia hosts unique and various freshwater biodiversity (Previšić et al., 2009; Maguire et al., 2018; Lovrenčić et al., 2020b, Buj et al., 2020; Gross et al., 2021). It is recognized as an important centre of native and endemic animal and plant species diversity as well as an important wildlife refuge area.

\footnotetext{
${ }^{*}$ Corresponding author: imaguire@biol.pmf.hr
}

Croatian freshwaters also represent hotspot of native European astacofauna by harbouring four native crayfish species with high genetic and morphological diversity comparing to other parts of Europe (Maguire et al., 2014; Jelić et al., 2016; Maguire et al., 2017; Lovrenčić et al., 2020a, b; Gross et al., 2021). However, crayfish as keystone species and ecosystem engineers are negatively affected and highly threatened by anthropogenic pressure on their habitat (Jussila et al., 2021). The noble crayfish Astacus astacus (L.) is the most highly appreciated indigenous crayfish species in Europe, known for its economic and cultural value. Previous studies have shown that the noble crayfish populations harbour the greatest genetic diversity in the south-eastern Europe where populations survived Pleistocene glaciations and subsequently re-colonised European freshwaters (Schrimpf et al., 2014; Gross et al., 2021). Natural distribution and genetic structure of $A$. astacus have been greatly altered and diminished across Europe due to habitat degradation, pollution, climate change, the introduction of nonindigenous invasive crayfish species, and a high amount of manmade translocations and stockings (Schrimpf et al., 2017). As a result, $A$. astacus has been classified as vulnerable by the IUCN Red List of Threatened Species (Edsman et al., 2010) and 
protected by international legislation (Annex III of the Bern Convention, Annex V of Habitat Directive (92/43/EEC). Moreover, $A$. astacus is listed as vulnerable in Croatia with a decreasing population trend (Gottstein et al., 2011), and is protected by national legislation ( $\mathrm{NN}$ 80/13). Effective protection of its existing populations requires conservation measures based on the comprehensive knowledge of the species, including information on its genetics and morphology (Sint et al., 2005; Souty-Grosset and Reynolds, 2009). Moreover, the outcomes of (re)introduction programmes, as one of the conservation approaches, highlighted the importance of using stocking material that will fit into its new habitat (Sint et al., 2005; Souty-Grosset and Reynolds, 2009).

Large-scale genetic analyses indicated the existence of seven divergent mitochondrial lineages within $\mathrm{A}$. astacus in Europe, with highly differentiated populations characterised by limited gene flow in the south-eastern Europe (Schrimpf et al., 2014, Laggis et al., 2017, Gross et al., 2021, Lovrenčić et al., 2022). Phylogenetic reconstruction based on the mitochondrial genes revealed that Croatian samples nested within two mitochondrial lineages, Lineage 2 and 4 sensu Schrimpf et al. (2014), with some populations harbouring crayfish from both lineages. Results of microsatellite analyses revealed low genetic diversity of $A$. astacus in central and north Europe due to frequent human translocations and/or founder effects due to postglacial re-colonization, and the highest genetic diversity in the south-eastern Europe (Laggis et al., 2017; Gross et al., 2021). Moreover, population genetic analysis showed the existence of two genetic groups (clusters) of A. astacus in Croatia (Lovrenčić et al., 2022).

Research of the freshwater crayfish morphology showed that they display great morphological diversity and phenotypic plasticity due to the influence of environment and/or genetic background (Haddaway et al., 2012; Perry et al., 2013). Furthermore, studies have been focused on evaluating morphological traits based on meristic and traditional morphometric in order to study different European crayfish species (Sint et al., 2005; Maguire and Dakić, 2011; Maguire et al., 2017; Đuretanović et al., 2017), while geometric morphometric characters were used in studies of Austropotamobius torrentium (Lovrenčić et al., 2020a), A. pallipes (Scalici and Bravi, 2012), Cambarus species (Helms et al., 2015) and Procambarus clarkii (Malavé et al., 2018). The first studies on A. astacus biogeography and taxonomy were based on the analyses of morphological and meristic characteristics (Albrecht, 1983; Karaman, 1929; Karaman, 1962; Karaman, 1963). Later, morphometric variation among A. astacus populations was studied based on the statistical analyses of a large set of morphometric parameters per crayfish in order to define characteristics that will distinguish different populations (Sint et al., 2005; Đuretanović et al., 2017). However, traditional morphometric multivariate analyses possess a comparatively low power in describing and visualising shape variation given that variables are usually strongly correlated with size and do not encode information about the relative location of the measurements. On the other hand, geometric morphometrics provides a solution to the problems inherent to traditional morphometric procedures by analysing shape using a Cartesian landmark coordinate system (Zelditch et al., 2004). This further allows for various methods of visualisation that can communicate complex morphological changes and detect subtle morphological differences within and among species (Klingenberg, 2013). Thus, in the present study we analysed the morphological features of A. astacus using geometric morphometrics for the first time.

The aim of this study was to verify whether or not there are significant morphological differences among $A$. astacus populations belonging to different previously established groups (Lovrenčić et al., 2022): (a) mitochondrial (genetic) lineages, (b) genetic clusters inferred from nuclear microsatellites, as well as (c) river basins and (d) habitat types (lotic, lentic). We hypothesized that morphology of A. astacus cephalon differs among different groups, and that our study will provide novel insights into biodiversity of this endangered species in the area of its high genetic diversity.

\section{Material and methods}

\subsection{Sampling}

This study was conducted by collecting adult crayfish from 15 populations across $A$. astacus distribution range in Croatia (Tab. 1, Fig. 1). Crayfish were collected with permission obtained from Ministry of Environmental Protection and Energy of the Republic of Croatia and in accordance with ethical standards. Catching was conducted either by hand during the night or with baited LiNi traps (Westman et al., 1978) that were left in the water body overnight. All sampled specimens were euthanised by freezing and identified to the species level according to the key of crayfish families in Europe (Holdich et al., 2006). Only adult (crayfish longer than $60 \mathrm{~mm}$ total length (Holdich et al., 2006)), uninjured, intermolt crayfish were used in the further analyses in order to minimise the influence of ontogenetic allometry. Also, the sexes were merged in the further analyses since previous studies showed that morphological differences in cephalon shape were not affected by sexual dimorphism in crayfish (Scalici et al., 2010, Helms et al., 2015; Lovrenčić et al., 2020a).

Crayfish specimens were grouped into a priori defined genetic lineages and genetic clusters, as well as their affiliation to river basins and habitat types (Tab. 1). Previous molecular phylogenetic analyses based on the two mitochondrial genes (COI and 16S RNA) were conducted on the same samples by Lovrenčić et al. (2022), and the results revealed the presence of two mitochondrial lineages of A. astacus in Croatia. These results enabled a priori classification of our specimens into three groups: Lineage 2 and Lineage 4 sensu Schrimpf et al. (2014) and the group containing specimens from both Lineages 2 and 4 (in further text abbreviated as Lineage 2/4). Likewise, previous population genetic analysis using nuclear microsatellites was conducted on the same specimens, and the results of Bayesian assignment test in the software STRUCTURE enabled a priori classification of each specimen into one of two genetic clusters: Genetic Cluster I and Genetic Cluster II sensu Lovrenčić et al. (2022). Moreover, specimens were also assigned to certain river basin (Drava, Sava or Danube) and habitat type (lentic or lotic). 
Table 1. List of studied Astacus astacus populations including information on the sample size (N), genetic lineage defined according to Lovrenčić et al. (2022), genetic cluster (I and II) defined according to Lovrenčić et al. (2022), river basin and habitat type. L2-Lineage 2 sensu Schrimpf et al. (2014), L4-Lineage 4 sensu Schrimpf et al. (2014), L2/L4-both lineages present in the same population.

\begin{tabular}{|c|c|c|c|c|c|c|}
\hline Population & Abbr. & $\mathrm{N}$ & Genetic lineage & Genetic cluster & Basin & Habitat \\
\hline Bednja & BED & 25 & L2 & I, II & Drava & lotic \\
\hline Bijela & BIJ & 7 & L4 & II & Sava & lotic \\
\hline Breznica & BRE & 11 & L4 & II & Sava & lotic \\
\hline Glogovica & GLO & 26 & L4 & II & Sava & lotic \\
\hline Ilova & ILO & 17 & L4 & II & Sava & lotic \\
\hline Kikovac & KIK & 18 & L4 & II & Sava & lotic \\
\hline Kutjevačka & KUT & 12 & L4 & II & Sava & lotic \\
\hline Motičnjak & MOT & 20 & $\mathrm{~L} 2 / \mathrm{L} 4$ & II & Drava & lentic \\
\hline Otuča & OTU & 2 & L2/L4 & II & Zrmanja & lotic \\
\hline Peratovica & PER & 4 & L4 & II & Sava & lotic \\
\hline Vuka & VUK & 19 & L4 & II & Danube & lotic \\
\hline Sloboština & SLO & 18 & L4 & II & Sava & lotic \\
\hline Totovec & TOT & 19 & L4 & I & Drava & lentic \\
\hline Veličanka & VEL & 29 & L4 & II & Sava & lotic \\
\hline Jaruga & JAR & 2 & L2 & II & Sava & lotic \\
\hline
\end{tabular}

\subsection{Geometric morphometrics and multivariate analyses}

Geometric morphometric methods (GM) focus on the geometry of shape that is estimated using the relative locations of landmarks and/or outlines rather than on linear measurements. In comparison with traditional morphometrics, it provides better quantification and visual presentation of the morphological structures, and allows high statistical sensitivity that detects small changes in the shape of morphological units (Adams et al., 2013). Due to numerous advantages, geometric morphometrics represent an innovative advancement in the analysis of morphology, and is now routinely used across the tree of life in all sorts of biological studies (Adams et al., 2013). Moreover, morphometrics is usually applied in combination with multivariate statistics to complement studies on crayfish genetics (Sint et al., 2007; Bertocchi et al., 2008) and ecology (Inoue et al., 2013). In the present study, following the procedure detailed in Lovrenčić et al. (2020a), GM analysis was focused on the cephalon shape using dorsal photographs of specimens. Images for digitisation were obtained by scanning dorsal view of crayfish cephalon using Epson Perfection V600 Photo scanner. Namely, dorsally positioned specimens were placed in a water basin on the flatbed scanner in order to obtain two-dimensional digital images. The GM analyses were performed using TPS 1.49 series software (Rohlf, 2015) and MorphoJ 1.06d (Klingenberg, 2011). Total of 14 landmarks were digitized using TpsDig v.2.17 (Rohlf, 2015) (Appendix 1). The number and selection of landmarks were based on the combination of points from Scalici et al. (2010), Scalici and Bravi (2012), and Lovrenčić et al. (2020a). Non-shape variation in translation, rotation and size from the original landmark configurations was removed by Generalized Procrustes Analysis (GPA) in MorphoJ 1.06d. The Canonical Variate Analysis (CVA) was performed using the same software in order to discriminate groups based on cephalon shape variation in different groups referred to in
Table 1. In order to find the shape characteristics that the best distinguish groups of specimens, CVA was chosen over Principal Component Analysis (PCA) since it maximizes the differences between groups, constructing variables in the way that it describes relative positions of groups in the sample, while PCA not, and it represents general variation in the sample (Zelditch et al., 2004). Further, CVA is one of the most used approaches to discriminate among groups since it maximizes distinction among groups in relation to the variation within groups (Campbell and Atchley, 1981). The results were reported as Procrustes and Mahalanobis distances with the respective $p$-values for these distances after permutation tests (10,000 iterations). Scatterplots of canonical scores were built to visualize the relationships among the a priori defined groups, while shape variation described by CVA was graphically depicted in the form of wireframes. In addition, CVA results were represented in scatterplots (CV1 vs CV2) with marginal density plots obtained using the packages ggplot2 v.3.3.5 (Wickham, 2016), cowplot v.1.1.1 (Wilke et al., 2019) and ggpubr v.0.4.0 (Kassambara, 2020) in R 4.0.0 (R Core Team, 2021).

We checked the existence of allometry (i.e., shape change related to size) by performing correlation analysis between Procrustes coordinates and centroid size. To assess whether or not differences between a priori groups are explained by size differences and allometry, we performed alternative CVAs removing the shape component due to allometry (Klingenberg, 2016). Both analyses were implemented in MorphoJ 1.06d (Klingenberg, 2011).

In order to account for the impact of uneven sample size in the a priori groups we created a routine that allows generating subsamples where each group has the same sample size by randomly selecting specimens. The number of specimens of each group was constrained by the group with the smallest sample size (i.e., genetic lineages $=22$, genetic clusters $=40$, river basins $=18$, and habitat types $=18$ ). This routine was repeated 250 times for each of the a priori classifications and CVA was carried out in all subsamples. Separation between 


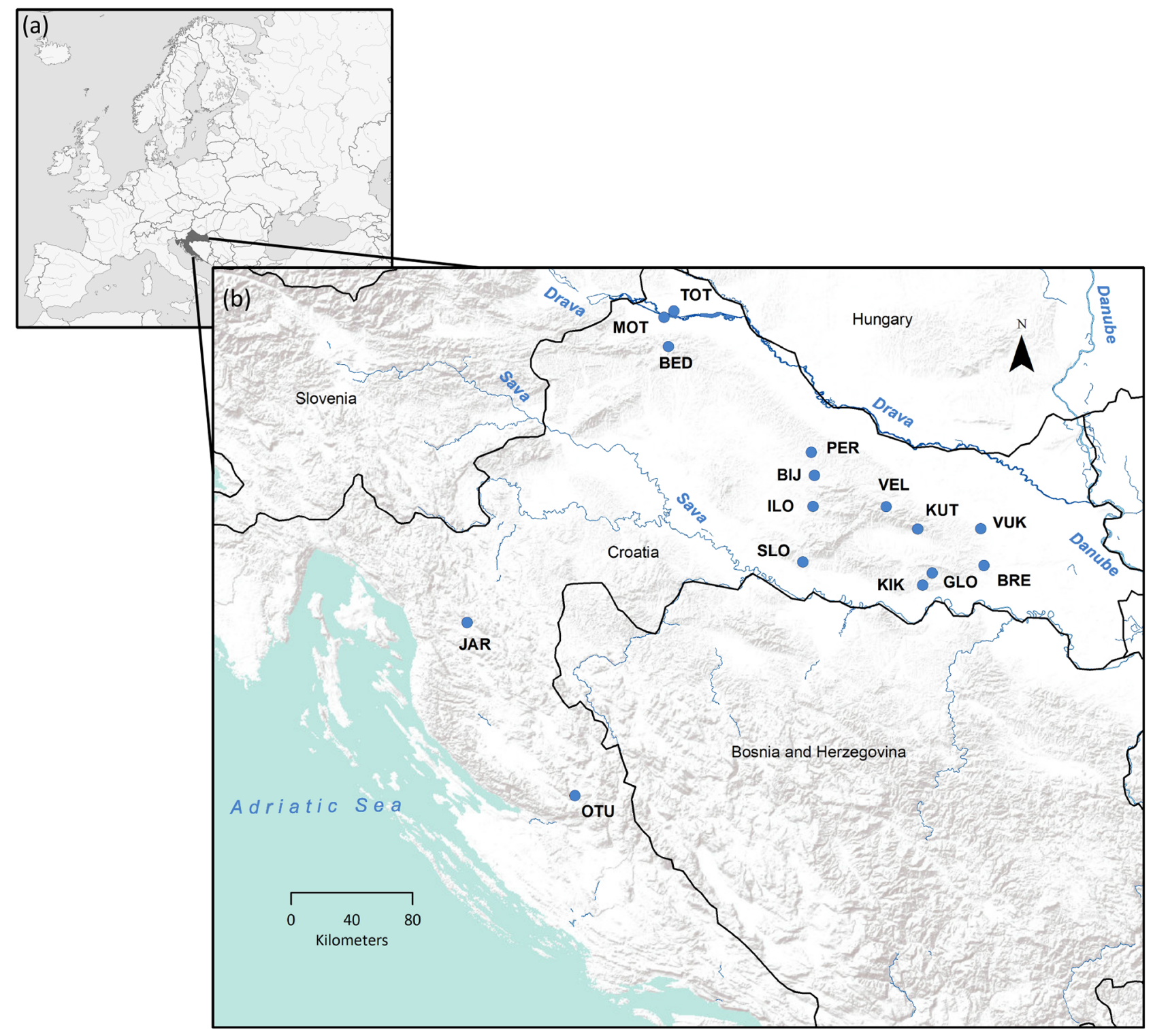

Fig. 1. Geographical location of the studied Astacus astacus populations (details about sampling sites are provided in Tab. 1). Map of Europe was adapted from https://commons.wikimedia.org/wiki/File:Croatia_in_Europe.svg. Map was prepared in QGIS 3.10 software and edited in Inkscape v. 0.91 .

groups was assessed visually with scatterplots (CV1 or CV1 vs CV2) and by plotting Mahalanobis distance dendrograms (only in classifications with more than two groups, i.e. genetic lineages and river basins). Analyses were performed in R 4.0.0 (R Core Team, 2021) using the packages geomorph v.4.0.1 (Adams and Otárola-Castillo, 2013), Morpho v.2.9 (Schlager et al., 2021), and shapes v.1.2.6 (Dryden, 2021). Complementarily, we tested for potential confounding effects between a priori classifications with similar partitioning of specimens within their groups (i.e., genetic lineage vs river basin, genetic cluster $v s$ habitat type, and river basin $v s$ habitat type). For this, we performed Principal Component Analysis (PCA) on the Procrustes coordinates and fitted linear models considering the first three PC scores (cumulative proportion of variance explained $\sim 56 \%$ ) as dependent variables and a priori classifications as factors. We compared models including each a priori classification separately ( $\sim$ genetic lineage; $\sim$ river basin; $\sim$ genetic cluster; $\sim$ habitat type) with models including combinations of these by pairs $(\sim$ genetic lineage + river basin; $\sim$ genetic cluster + habitat type; $\sim$ river basin + habitat type). Akaike information criterion (AIC) was then employed to assess which models fit the data better (i.e., those with lower AIC values). A better support for models containing a single factor over those containing pairs of factors would be in agreement with the presence of important confounding effects; while the contrary would support that both factors contribute to explain shape variability within our sample. Linear models were fitted with the aov() function in the R package Stats v. 4.2 .0 (R Core Team, 2021) and AIC values were obtained in the R package AICcmodavg v. 2.3.1 (Mazerolle, 2021). We considered a significance threshold of $p<0.05$ for all the analyses. 
(A) Genetic lineage

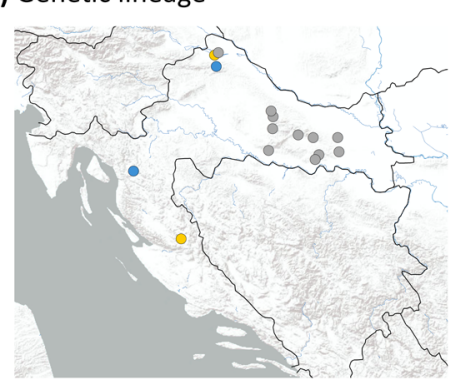

(B) Genetic cluster
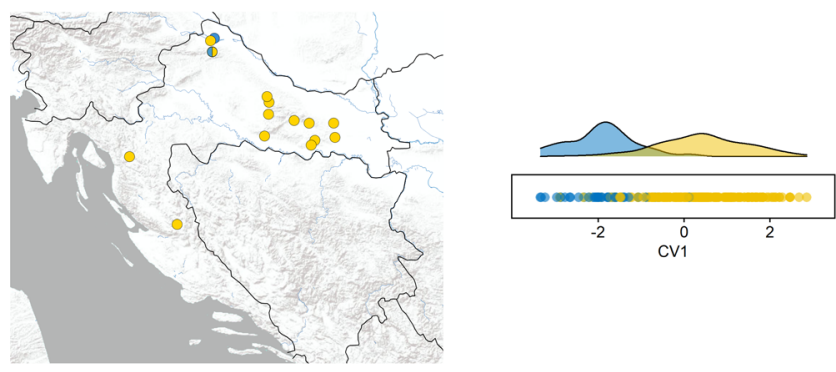

- Cluster I

- Cluster II

-CV1
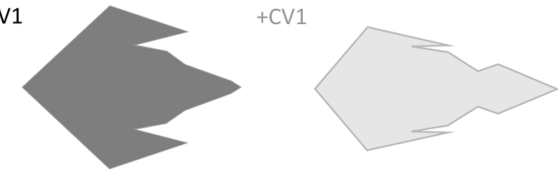

$-\mathrm{CV} 2$
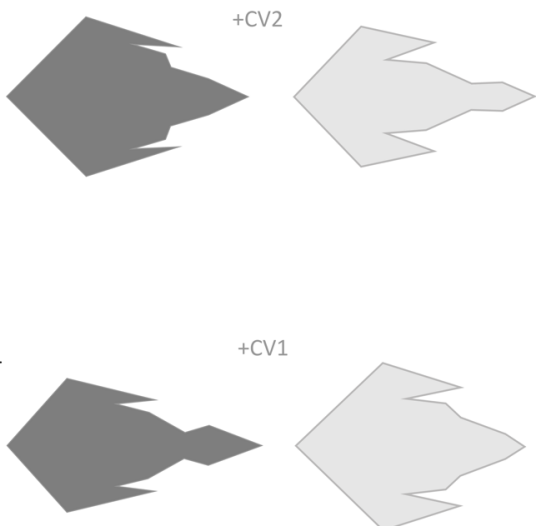

(C) River basin
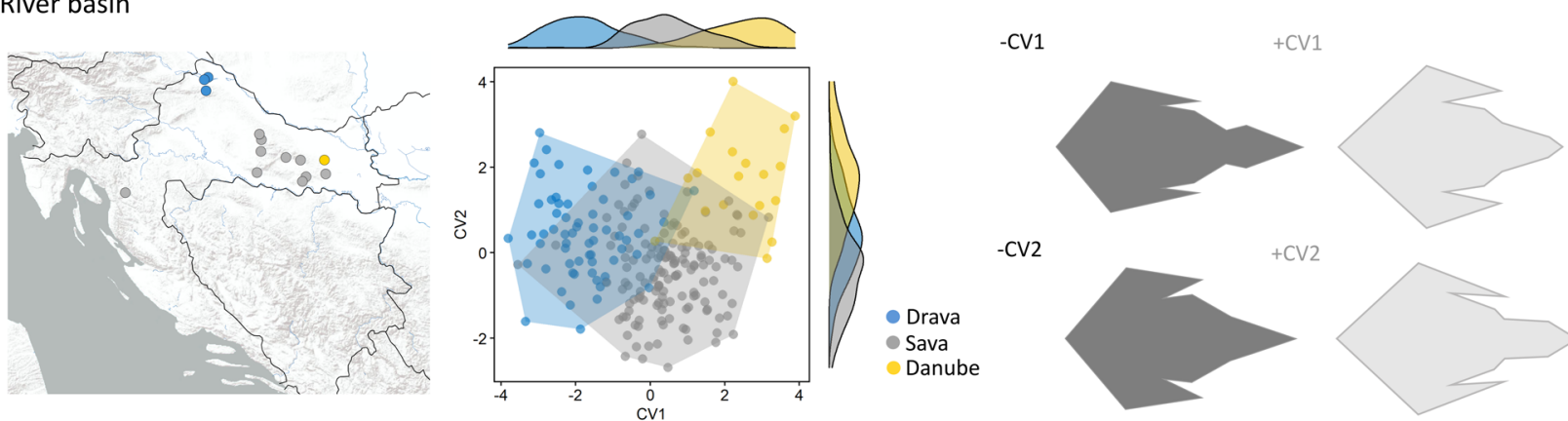

$-\mathrm{CV} 2$
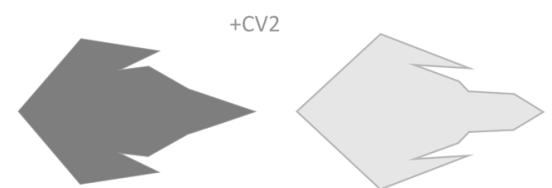

(D) Habitat type
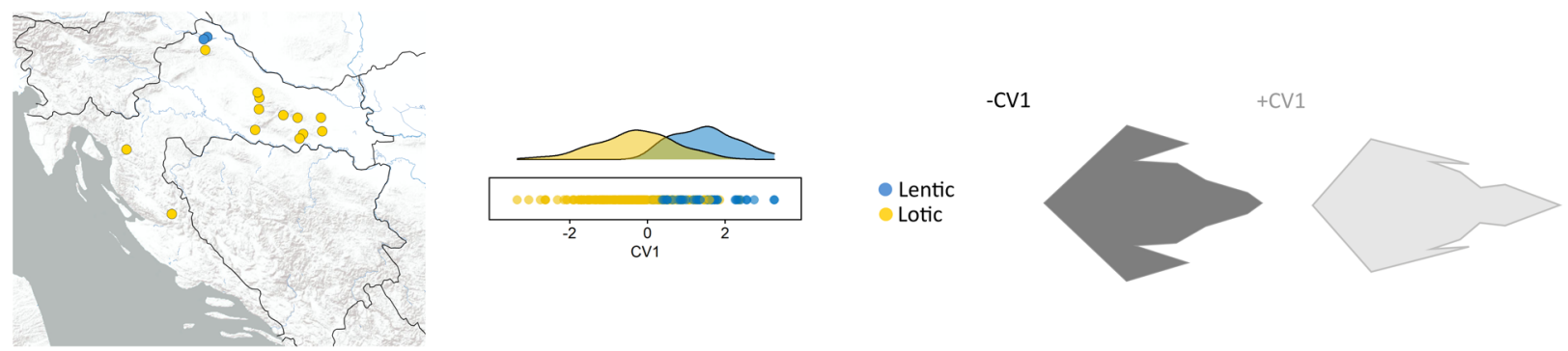

Fig. 2. Cephalon shape variation of Astacus astacus revealed by Canonical Variate Analysis. Scatter plots of the first two canonical variate axes (CV1 and CV2) with associated wireframe representations depicting shape changes along positive and negative extremes of the axes. Dark grey landmark wireframe configurations represent cephalon morphologies along negative extremes, while light grey landmark wireframe configurations represent cephalon morphologies along positive extreme. Different colour dots represent different groups: (A) genetic lineage, (B) genetic cluster, (C) river basin, (D) habitat type, with maps showing their distribution in Croatia.

\section{Results}

\subsection{Cephalon shape variation according to $A$. astacus genetic lineages}

Cephalon shape variation analyses included 229 crayfish (Tab. 1). Results of CVA showed the differentiation among
A. astacus genetic lineages based on the cephalon shape (Fig. 2). The first two canonical variates (CVs) explained entire shape variation: CV1 accounted for $71.65 \%$, while the CV2 accounted for $28.35 \%$ of the variability. The CVA separated to some extent the specimens into three groups, corresponding to the previously defined genetic lineages. CV1 separated, with somewhat overlap, the Lineage 4 from Lineage 2 and 
Table 2. Procrustes distances (below diagonal) and Mahalanobis distances (above diagonal) between different groups of Astacus astacus with $p$-values from permutation tests (10,000 permutation rounds).

\begin{tabular}{llll}
\hline Procrustes and Mahalanobis distances & & & Lineage $2 / 4$ \\
\hline A) Genetic lineage & Lineage 2 & $2.103^{* *}$ & $2.175^{* *}$ \\
Lineage 2 & & & $2.038^{* *}$ \\
Lineage 2/4 & $0.031^{* *}$ & $0.024^{*}$ & II \\
Lineage 4 & $0.034^{* *}$ & $2.324^{* *}$ & Sava \\
B) Genetic cluster & I & Danube & $2.397^{* *}$ \\
I & $0.029^{* *}$ & $4.393^{* *}$ & $2.899^{* *}$ \\
II & Drava & & $0.036^{* *}$ \\
C) River basin & & Lotic & $1.811^{* *}$ \\
Drava & $0.057^{* *}$ & \\
Danube & $0.026^{* *}$ & Lentic & \\
Sava & & & \\
D) Habitat type & $0.025^{* *}$ & & \\
Lentic & &
\end{tabular}

*Indicates statistical significance at $p<0.05$.

**Indicates statistical significance at $p<0.0001$.

Lineage $2 / 4$, while CV2 separated, with certain overlap, the Lineage 2 and mixed Lineage 2/4 (Fig. 2A). Overall cephalon shape, as quantified by Procrustes and Mahalanobis distances, differed among the genetic lineages, with all distances being statistically significant (Tab. 2). Randomised subsampling revealed much better separation among genetic lineages with slight overlap (Appendix 2).

Shape changes that contributed to the distinction among crayfish from different lineages were mostly visible in the apical part of the cephalon (rostrum), the lateral edge of the cervical groove, the placement of the postorbital ridges, and the overall cephalon length and width (Fig. 2A).

Shape change along the CV1 axis was mostly determined by the length and width of the cephalon, the width of lateral edge of the cervical groove, and the placement of the postorbital ridges (Fig. 2A). Shape changes along $+\mathrm{CV} 1$ were characterised by enlargement of the rostrum, elongating and narrowing of the cephalon, narrowing of the lateral edge of the cervical groove, and the two postorbital ridges placed closer to the lateral edge of the body. These characteristics were more pronounced in some specimens belonging to the Lineage 2 and Lineage $2 / 4$. In contrast, $-\mathrm{CV} 1$ was related to the reduction of rostrum size, both length and width, shortening and widening of the cephalon, widening of the lateral edge of the cervical groove, with two postorbital ridges placed distant from the lateral edge of the body. These characteristics prevailed in some specimens from Lineage 4.

Shape changes along + CV2 were generally characterised by larger rostrum, narrower cephalon, shortening of the lateral edge of the carapace, and the two postorbital ridges placed distant from the lateral edge of the body and rostrum. These morphological characteristics were generally pronounced in the crayfish from the Lineage 2 and partially Lineage 4 . Shape changes along $-\mathrm{CV} 2$ were pronounced in the crayfish from the Lineage 2/4 and partially Lineage 4 , and were characterised by smaller rostrum, wider cephalon, widening of the lateral edge of the carapace, and with the two postorbital ridges placed closer to the lateral edge of the body (Fig. 2A).

\subsection{Cephalon shape variation according to $A$. astacus genetic cluster}

Results of CVA showed the differentiation between crayfish from different genetic clusters (Fig. 2B). Shape changes along the positive extreme $(+\mathrm{CV} 1)$ included crayfish from the Genetic Cluster II sensu Lovrenčić et al. (2022, Tab. 1) that were characterised by shorter and narrower rostrum, wider cephalon, and wider lateral edge of the cervical groove. Contrary, shape changes along the negative extreme (-CV1) indicated crayfish from the Genetic Cluster I sensu Lovrenčić et al. (2022, Tab. 1), and were characterised by longer and larger rostrum, elongated and narrower cephalon, and narrower lateral edge of the cervical groove (Fig. 2B). Procrustes and Mahalanobis distances separated significantly crayfish from different clusters (Tab. 2B). Randomised sampling revealed similar results (Appendix 3).

\subsection{Cephalon shape variation according to river basin}

The CVA showed that shape variation among crayfish from three river basins was explained in the first two dimensions of the shape space (Fig. 2C). The first two canonical variates (CVs) explained the shape variation: CV1 accounted for $78.70 \%$, while the CV2 accounted for $21.30 \%$ of the variability. Procrustes and Mahalanobis distances separated crayfish from different basins, all being statistically significant (Tab. 2C). Randomised sampling showed much better separation among crayfish belonging to different river basins with no overlap (Appendix 4).

The CV1 differentiated crayfish from the Drava and Danube River basins: the crayfish from the Danube basin (shape associated with the positive extreme, along $+\mathrm{CV} 1$ ) had smaller rostrum, smaller and wider cephalon, wider lateral edge of the cervical groove, and the two postorbital ridges placed distant from the lateral edge of the body and closer to the rostrum, than the crayfish from the Drava basin 
(shape associated with the negative extreme, along -CV1) that were characterised by narrower and elongated cephalon with larger rostrum, narrower lateral edge of the cervical groove, and the two postorbital ridges placed closer to the lateral edge of the body (Fig. 2C). Crayfish from Sava basin occupied an intermediate position in the morphospace with a high degree of overlapping with two other basins.

The CV2 partly separated crayfish from the Danube and Sava River basins with the shape changes mostly pronounced in the width of the lateral edge of the carapace and cervical groove, the rostrum, and the placement of the postorbital ridges (Fig. 2C). Shape changes along the positive extreme (+CV2) were characterised by wider lateral edge of the carapace and cervical groove, wider rostrum apex, and the two postorbital ridges and spines placed closer to the lateral edge of the body. These characteristics were mostly present in the specimens from the Danube basin. In contrast, some of the crayfish from the Sava basin (shape associated with the negative extreme, along -CV2) were characterised by narrower lateral edge of the carapace and cervical groove, and the two postorbital ridges placed distant from the lateral edge of the body.

\subsection{Cephalon shape variation according to habitat type}

Results of CVA showed the differentiation between crayfish from different habitat types (Fig. 2D). Shape changes along the positive extreme $(+\mathrm{CV} 1)$ designated the crayfish from the lentic habitats (lakes), and were characterised by longer and larger rostrum, elongated and narrower cephalon, narrower lateral edge of the cervical groove, but wider lateral edge of the carapace. Contrary, shape changes along the negative extreme $(-\mathrm{CV} 1)$ indicated crayfish from the lotic habitats (rivers and streams) that were characterised by shorter and narrower rostrum, shorter and wider cephalon, wider lateral edge of the cervical groove, but narrower lateral edge of the carapace (Fig. 2D). Randomised sampling revealed similar results (Appendix 5). Procrustes and Mahalanobis distances separated significantly crayfish from different habitats (Tab. 2D).

\subsection{Allometry analyses}

We detect allometric change affecting the cephalon of $A$. astacus ( $p$-value $<0.0001)$, where bigger specimens show an expansion of posterior region of the head, narrower rostrum, and longer lateral edge of the carapace, in comparison with smaller specimens (Appendix 6). However, proportion of variation for which the allometric regression accounts is comparatively low (7.66 \%). Groups within each a priori classification are still separated by CVA when removing allometric component of shape and the morphological changes associated to each $\mathrm{CV}$ are equivalent to those of the original analysis (Appendix 7). Therefore, size of individuals did not affect our results.

\subsection{Linear model fit}

The results of the linear modelling showed that crayfish cephalon shape significantly differed among genetic lineages $\left(p\right.$-value $\left.=3.11 * 10^{-6}\right)$, genetic clusters $\left(p\right.$-value $\left.=1.64 * 10^{-4}\right)$, and habitat types $\left(p\right.$-value $\left.=3.05 * 10^{-2}\right)$, while we did not observe significant effect based on river basins ( $p$-value $=$ $9.1^{*} 10^{-1}$ ) (see Appendix 8 for detailed results). The models including genetic clusters + habitat types and river basins + habitat types as factors fit the data better than the models including those separately (AIC genetic clusters + habitat types $=$ 1236.70; AIC river basins + habitat types $=1256.68 ;$ AIC genetic clusters $=1250.80 ; \stackrel{\text { river }}{\text { AlC }}$ hasins + habitat types $=1260.42$; AIC river basins $=$ 1267.03); while the model including genetic lineages + river basins as factors fits the data better than the model including only river basins and slightly worse than the model including only genetic lineages (AIC lineages + river basins $=1244.28$; AIC lineages $=1241.53$; AIC river basins $=1267.03)$.

\section{Discussion}

The present study provides important insight into the morphological diversity of the studied $A$. astacus populations through the application of geometric morphometrics. This approach was used for depicting cephalon shape differences/ differentiation among $A$. astacus specimens. Our study revealed existence of variation in the cephalon shape among A. astacus inhabiting Croatian freshwater habitats. Results indicated that cephalon morphology differs among mitochondrial lineages, but also between microsatellite clusters, among river basins and between habitat types. Additionally, these results were consistent after applying randomization routines to correct uneven sample size of a priori defined groups, supporting that this aspect has no major impact on our analyses. Even though the presence of allometry is well supported, this seems to play a minor role in the morphological differentiation of the different a priori defined groups, as results remain the same after removing allometric component of shape. Moreover, differences in the crayfish cephalon shape among a priori defined groups are also supported by PCA and derived linear models, except for the case of river basins. However, the later might be due to the fact that results from PCA, contrary to those from CVA, not necessarily reflect differences between predefined groups, even if they exist (Krzanowski, 2000).

Majority of studies on the morphological variability of freshwater crayfish have been based on traditional morphometrics that includes multivariate analyses of crayfish body linear measures to quantify shape (Ghia et al., 2006; Sint et al., 2006; Bertocchi et al., 2008; Bök et al., 2010; Maguire and Dakić, 2011; Benzer et al., 2017; Maguire et al., 2017). In our study, we applied geometric morphometrics, in combination with CVA, on $A$. astacus for the first time. This approach has allowed us to establish a comparative framework, based on quantitative and statistically tractable data, where new specimens can be included and classified into predefined groups, with associated probabilities. This is in fact one of the direct applications of CVA (McKeown and Schmidt, 2013) and, in our case, it would allow to infer, for example, genetic or ecological aspects from morphology.

Freshwater crayfish exhibit high intraspecific morphological variation that reflects both environmental influence and/or genetic background (Sint et al., 2005; Sint et al., 2007; Ghia et al., 2006; Bertocchi et al., 2008; Mathews et al., 2008; Cataudella et al., 2010; Haddaway et al., 2012; Perry et al., 2013; 
Helms et al., 2015; Rudolph et al., 2016). Moreover, they display phenotypic plasticity, meaning that individual phenotype is not only determined by its genotype, but can also be shaped through habitat and its local environmental conditions (Haddaway et al., 2012). In general, species can exhibit a wide phenotypic variation due to their widespread distribution within heterogeneous habitats, genetic and behavioural differences among individuals or populations, and ontogenetic and evolutionary forces that can also affect their phenotype (Rudolf et al., 2016). Phenotypic plasticity can affect not only the morphological, but also physiological and behavioural aspects of an organism, including its life history traits (Sommer, 2020). Phenotypic plasticity enables adaptations to the local ecological conditions that may lead to pronounced morphological differences between populations, but also may portray populations living under similar ecological conditions that in the end will exhibit similar morphology (Sint et al., 2005). Even though crayfishes exhibit morphological plasticity as a consequence of genetic variation or environmental factors or their interaction, our study corroborates geometric morphometrics as a valuable tool in studying variability and slight morphological differences. In our case, application of GM on the a priori defined groups (e.g., genetic groups) helped us to perceive morphological features (e.g., shape of rostrum) that characterise those groups and to separate them to some extent. Moreover, this study confirmed the anterior part of the crayfish body, e.g. cephalon and rostrum shape, as a source of variation within and among populations as demonstrated for Austropotamobius torrentium (Lovrenčić et al., 2020a). Further, it confirmed the advantage of using carapace and particularly cephalon in studying variation, since measurements are not affected by loss, regeneration, or abdominal muscle contractions (Sint et al., 2005).

Mitochondrial DNA sequences revealed the existence of several distinct evolutionary lineages within A. astacus in Europe (Schrimpf et al., 2014, Laggis et al., 2017, Gross et al., 2021, Lovrenčić et al., 2022), so one of our aims was to determine whether two genetic lineages identified in Croatian populations differ in cephalon shape, and if it can be used as a feature that can be used to distinguish lineages. Our study showed slight differences in the cephalon shape between crayfish from different lineages revealed by mitochondrial DNA analyses (Lovrenčić et al., 2022). Observed differences could be the consequence of species evolutionary history. According to Schrimpf et al. (2014), A . astacus probably survived last glaciations in the western and southern parts of Balkans, as well as in the lower part of the Danube basin, and then spread northward and westward along the Danube drainage system. The observed differences among genetic lineages in morphology probably mirror the long-term separation of $A$. astacus populations, experienced during the cold periods of the Pleistocene when nearly all of the central and northern Europe was unsuitable for crayfish, and therefore, they were mainly confined to refugia in the Iberian, Italian, and Balkan Peninsulas (Hewitt, 2011). The results of phylogenetic analysis are congruent with shape variation to some extent; genetic lineages described within $A$. astacus are still evolutionary very young and mostly unsupported in the phylogenetic reconstruction (Gross et al., 2021), which is also reflected in morphology. In conclusion, observed changes/ differences in cephalon shape reflect phylogenetic reality with numerous individuals overlapping /without clear separation among/between genetic lineages. Since model including genetic lineages + river basin fits the data better than the model including only river basins and slightly worse than the model including only genetic lineages we can conclude that river basin does not contribute to obtained separation.

Considering groups based on the previous microsatellite genotyping (Lovrenčić et al., 2022), studied crayfish belong to two distinct genetic clusters. Most of the individuals were assigned to Genetic Cluster II, whereas the Genetic Cluster I grouped individuals from populations TOT and partly BED, with the sign of possible admixture in BED. Our results, both nonrandomised and randomised, revealed that morphology of cephalon differs between the two genetic clusters. Since models including genetic cluster and habitat slightly better fit the data than single models, we may say that both factors contribute to explain shape variability.

Astacus astacus showed variation in the cephalon shape among three different river basins: Sava, Drava and Danube. The geometric morphometrics suggested separation among populations belonging to separate river basin which was especially pronounced for the individuals from the Drava and Danube River basins. This is contrary to findings by Malato et al. (2017) who studied differences between fish from genus Rhoadsia and concluded that fish body shape from different drainages overlaps. However, our results are concordant with findings of Jerry and Cairns (1998) who studied Australian bass and revealed morphological differences among populations belonging to different riverine drainages.

Finally, our results, both nonrandomised and randomised, showed morphological variation between different habitat types, i.e. lakes and rivers. Crayfish from lentic sites had a narrower, more elongated cephalon and rostrum than those from lotic sites with shorter and wider cephalon (generally smaller head, rostrum and apex). The morphological characteristics that differentiate specimens from different habitats can be correlated with lifestyle habits resulting in an improved performance of a species (Rudolph et al., 2016). For example, streamlined body shape is associated with a reduced resistance to the water flow, which might mitigate drag and increase opportunities of finding shelters. This pattern of morphological difference is similar to that observed in other decapods crustaceans, such as the case reported by Perry et al. (2013) for Orconectes rusticus. Moreover, our results showed that crayfish from lotic habitats possess less pronounced rostrum that can, according to Perry et al. (2013), facilitate their life among the rocks on the river bed, the search for food and shelter from predators. This finding is consistent with the results of Rudolph et al. (2016) that studied the only South American parastacid that inhabits both rivers and lakes, Samastacus spinifrons. Their study revealed that lake specimens exhibit more robust body, more pronounced rostrum and more elongated, less thick claws and longer phallic papillae compared to fluvial populations. This phenomenon explains variations in morphological forms that occur as a result of the ability of organisms/genotype to produce distinct phenotypes in response to different environmental conditions (Sommer, 2020). Furthermore, Perry et al. (2013) studied the effect of water velocity on the size and shape of invasive crayfish Orconectes rusticus, and reported that specimens that inhabit streams with high-velocity water flow are slender than those that inhabit lakes and streams with low-velocity flow. They 
confirmed that elevated water velocity can affect crayfish morphology with crayfish size as an important factor mediating the response to water velocity what is in accordance with results obtained in our study. Therefore, both genetic variation and phenotypic plasticity play important roles in predictable phenotypic differentiation across flow regimes (Langerhans, 2008; Perry et al., 2013).

In conclusion, we applied geometric morphometrics to address cephalon shape variation of the noble crayfish, and it proved as appropriate for studying its morphology. Moreover, analyses of cephalon showed as suitable for separation of different groups. Overall, our results indicated the existence of morphological diversity of the noble crayfish in Croatia. Our study showed differences of the cephalon shape based on crayfish affiliation to different genetic lineages, genetic clusters, river basins and habitat types (lotic, lentic). Despite some equivalence in the partitioning of specimens within the groups of the different a priori classifications exists, our analyses based on PCA and linear modelling show that these factors contribute in different ways to the shape variation of our sample which denotes that, if present, confounding effects are not important. This is further supported by the fact that shape changes related to the separation of groups are different for each of the considered a priori classifications. Therefore, observed morphological characteristics are attributed not only to genetics but also to environmental factors that speaks in favour of their phenotypical plasticity.

\section{Supplementary Material}

Appendix 1. Position of the 14 landmarks on the dorsal side of Astacus astacus cephalon. Landmarks 1, 2 and 14 describe apex; Landmarks 1, 2, 3, 4, 12, 13 and 14 describe rostrum; Landmarks 7 and 8 describe lateral edge of cervical groove; Landmarks 4, 5, 6, 10, 11 and 12 describe postorbital ridges.

Appendix 2. Cephalon shape variation of Astacus astacus revealed by Canonical Variate Analysis on a priori defined genetic lineages accounting for uneven sample size. Scatter plots of the first two canonical variate axes (CV1 and CV2) are shown. Different colour dots represent individuals assigned to certain genetic lineages (blue, Lineage 2; grey, Lineage 4; yellow, Lineages 2/4). Separation of the genetic lineages is also represented by Mahalanobis distance dendrograms.

Appendix 3. Cephalon shape variation of Astacus astacus revealed by Canonical Variate Analysis on a priori defined genetic clusters accounting for uneven sample size. Scatter plots of the first canonical variate axis (CV1) are shown. Different colour dots represent individuals assigned to certain genetic cluster (blue, Cluster I; yellow, Cluster II).

Appendix 4. Cephalon shape variation of Astacus astacus revealed by Canonical Variate Analysis on individuals affiliated to different river basin accounting for uneven sample size. Scatter plots of the first two canonical variate axes (CV1 and CV2). Different colour dots represent individuals assigned to certain river basin (blue, Drava; grey, Sava; yellow, Danube). Separation of the river basins is also represented by Mahalanobis distance dendrograms.

Appendix 5. Cephalon shape variation of Astacus astacus revealed by Canonical Variate Analysis on individuals affiliated to different habitat type accounting for uneven sample size. Scatter plots of the first canonical variate axis (CV1). Different colour dots represent individuals assigned to certain habitat type (blue, lentic; yellow, lotic).

Appendix 6. Regression analysis between shape and centroid size showing associated shape changes corresponding to positive (upper) and negative (lower) extremes (shape changes are displayed with scale factors magnified x100 to ease interpretation).

Appendix 7. Cephalon shape variation of Astacus astacus revealed by Canonical Variate Analysis after removing allometric component of shape. Scatter plots of the first two canonical variate axes (CV1 and CV2) with associated wireframe representations depicting shape changes along positive and negative extremes of the axes. Dark blue landmark wireframe configurations represent cephalon morphologies along extremes, while light blue average landmark wireframe configurations. Different colour dots represent different groups: (A) genetic lineage, (B) genetic cluster, (C) river basin, (D) habitat type.

Appendix 8. Detailed results of linear models.

The Supplementary Material is available at https://www.kmae. org $/ 10.1051 / \mathrm{kmae} / 2022006 / \mathrm{olm}$.

Acknowledgments. This research was funded by the Croatian Science Foundation (CLINEinBIOta-IP-2016-06-2563) and Leona Lovrenčić through ESF (DOK-2018-01-9589). We would like to thank to Dr. Mišel Jelić for the use of scanner, Anja Eloise Livaić for help in scanning the crayfish, and Adam P. Maguire for English language revision and editing. Also, our gratitude goes to Reviewers for their constructive criticism that helped us improving original version of this MS.

\section{References}

Adams DC, Otárola-Castillo E. 2013. Geomorph: an R package for the collection and analysis of geometric morphometric shape data. Methods Ecol Evol 4: 393-399.

Adams DC, Rohlf FJ, Slice DE. 2013. A field comes of age: geometric morphometrics in the 21st century. Hystrix 24: 7-14.

Albrecht H. 1983. Besiedlungsgeschichte und ursprünglich holozane verbreitung der europäischen Flusskrebse. Spixiana 6: 61-77.

Benzer SS, Benzer R, Gunal C. 2017. Artificial neural networks approach in morphometric analysis of crayfish (Astacus leptodactylus) in Hirfanlı Dam Lake. Biologia 72: 527-535.

Bertocchi S, Brusconi S, Gherardi F, Buccianti A, Scalici M. 2008. Morphometrical characterization of the Austropotamobius pallipes species complex. J Nat Hist 42: 2063-2077.

Bök TD, Harloğlu MM, Deval MC. 2010. A study on the morphometric characteristics of Astacus leptodactylus inhabiting the Thrace region of Turkey. Knowl Manag Aquat Ecosyst 397: 05.

Buj I, Marčić Z, Čavlović K, et al. 2020. Multilocus phylogenetic analysis helps to untangle the taxonomic puzzle of chubs (genus Squalius: Cypriniformes: Actinopteri) in the Adriatic basin of Croatia and Bosnia and Herzegovina. Zool J Linnean Soc 189: 953-974.

Cataudella R, Paolucci M, Delaunay C, Ropiquet AH, Baslamo M, Grandjean F. 2010. Genetic variability of Austropotamobius italicus in the Marches region: implications for conservation. Aquat Conserv 20: 261-268.

Campbell NA, Atchley WR. 1981. The geometry of canonical variate analysis. Syst Biol 30: 268-280. 
Collen B, Whitton F, Dyer EE, et al. 2014. Global patterns of freshwater species diversity, threat and endemism. Glob Ecol Biogeogr 23: 40-51.

Dryden IL. Package 'shapes': Statistical Shape Analysis. R Package Version 1.2.6.

Dudgeon D, Arthington AH, Gessner MO, et al. 2006. Freshwater biodiversity: importance, threats, status and conservation challenges. Biol Rev Camb Philos Soc 81: 163-182.

Đuretanović S, Jaklič M, Milošković A, et al. 2017. Morphometric variations among Astacus astacus populations from different regions of the Balkan Peninsula. Zoomorphology 136: 19-27.

Edsman L, Füreder L, Gherardi F, Souty-Grosset C. 2010. Astacus astacus. In: IUCN 2010, IUCN Red List of Threatened Species. http://www.iucnredlist.org

Ghia D, Nardi PA, Negri A, et al. 2006. Syntopy of A. pallipes and A. italicus: genetic and morphometrical investigations. Bull $\mathrm{Fr}$ Pêche Piscic 380-381: 1001-1018.

Gottstein S, Hudina S, Lucić A, Maguire I, Ternjej I, Žganec K. 2011. Crveni popis rakova (Crustacea) slatkih i bočatih voda Hrvatske (Red list of freshwater and brackishwater crustaceans of Croatia). Državni zavod za zaštitu prirode (State Institute for Nature Protection), Zagreb, Croatia (in Croatian).

Gross R, Lovrenčić L, Jelić M, et al. 2021. Genetic diversity and structure of the noble crayfish populations in the Balkan Peninsula revealed by mitochondrial and microsatellite DNA markers. PeerJ 9: e 11838.

Haddaway NR, Mortimer RJ, Christmas M, Grahame JW, Dunn AM. 2012. Morphological diversity and phenotypic plasticity in the threatened British white-clawed crayfish (Austropotamobius pallipes). Aquat Conserv 22: 220-231.

Helms BS, Vaught RC, Suciu SK, Santos SR. 2015. Cryptic diversity within two endemic crayfish species of the Southeastern US revealed by molecular genetics and geometric morphometrics. Hydrobiologia 755: 283-298.

Hewitt GM. 2011. Mediterranean peninsulas: the evolution of hotspots. In Zachos F, Habel J, eds. Biodiversity hotspots. Berlin: Springer, 123-147.

Holdich DM, Haffner P, Noël PY. 2006. Species files. In SoutyGrosset C, Holdich DM, Noël PY, Reynolds JD, Haffner P, eds., Atlas of Crayfish in Europe, Patrimoines naturels, Muséum national d'Histoire naturelle, Paris, 49-131.

Inoue K, Hayes DM, Harris JL, Christian AD. 2013. Phylogenetic and morphometric analyses reveal ecophenotypic plasticity in freshwater mussels Obovaria jacksoniana and Villosa arkansasensis (Bivalvia: Unionidae). Ecol Evol 3: 2670-2683.

Jelić M, Klobučar GI, Grandjean F, Puillandre N, Franjević D, Futo M, et al. 2016. Insights into the molecular phylogeny and historical biogeography of the white-clawed crayfish (Decapoda, Astacidae). Mol Phylogenet Evol 103: 26-40.

Jerry DR, Cairns SC. 1998. Morphological variation in the catadromous Australian bass, from seven geographically distinct riverine drainages. $J$ Fish Biol 52: 829-843.

Jussila J, Edsman L, Maguire I, Diéguez-Uribeondo J, Theissinger K. 2021. Money Kills Native Ecosystems: European Crayfish as an Example. Front Ecol Evol 9: e648495.

Karaman S. 1929. Die Potamobiiden Jugoslaviens. Glas Zemalj Muz Bosni Herceg 41: 147-150.

Karaman MS. 1962. Ein Beitrag zur Systematik der Astacidae (Decapoda). Crustaceana 3: 173-191.

Karaman MS. 1963. Studie der Astacidae (Crustacea, Decapoda). Hydrobiologia 22: 111-132.

Kassambara A. 2020. ggpubr: "ggplot2" Based Publication Ready Plots. R Package Version 0.4.0.
Klingenberg CP. 2011. MorphoJ: an integrated software package for geometric morphometrics. Mol Ecol Resour 11: 353-357.

Klingenberg CP. 2013. Visualizations in geometric morphometrics: how to read and how to make graphs showing shape changes. Hystrix 24: 15-24.

Klingenberg CP. 2016. Size, shape, and form: concepts of allometry in geometric morphometrics. Dev Genes Evol 226: 113-137.

Krzanowski WJ. 2000. Principles of Multivariate Analysis: A User's Perspective. Oxford: Oxford University Press, 586 p.

Laggis A, Baxevanis AD, Charalampidou A, Maniatsi S, Triantafyllidis A, Abatzopoulos T. 2017. Microevolution of the noble crayfish (Astacus astacus) in the Southern Balkan Peninsula. BMC Evol Biol 17: 122.

Langerhans RB. 2008. Predictability of phenotypic differentiation across flow regimes in fishes. Integr Comp Biol 48: 750-768.

Lovrenčić L, Pavić V, Majnarić S, Abramović L, Jelić M, Maguire I. 2020a. Morphological diversity of the stone crayfish - traditional and geometric morphometric approach. Knowl Manag Aquat Ecosyst 421: 1.

Lovrenčić L, Bonassin L, Boštjančić LJL, et al. 2020b. New insights into the genetic diversity of the stone crayfish: taxonomic and conservation implications. BMC Evol Biol 20: 146.

Lovrenčić L, Temunović M, Gross R, Grgurev M, Maguire I. 2022. Integrating population genetics and species distribution modelling to guide conservation of the noble crayfish, Astacus astacus, in Croatia. Sci Rep 12: 2040.

Maguire I, Dakić L. 2011. Comparative analyses of Astacus leptodactylus morphological characteristics from Croatia and Armenia. Biologia 66: 491-498.

Maguire I, Podnar M, Jelić M, et al. 2014. Two distinct evolutionary lineages of the Astacus leptodactylus speciescomplex (Decapoda: Astacidae) inferred by phylogenetic analyses. Invertebr Syst 28: 117-123.

Maguire I, Marn N, Klobučar G. 2017. Morphological evidence for hidden diversity in the threatened stone crayfish Austropotamobius torrentium (Schrank, 1803) (Decapoda: Astacoidea: Astacidae) in Croatia. J Crustacean Biol 37: 7-15.

Maguire I, Klobučar G, Žganec K, Jelić M, Lucić A, Hudina S. 2018. Recent changes in distribution pattern of freshwater crayfish in Croatia - threats and perspectives. Knowl Manag Aquat Ecosyst 419: 2.

Malato G, Shervette VR, Navarrete Amaya R, et al. 2017. Parallel body shape divergence in the Neotropical fish genus Rhoadsia (Teleostei: Characidae) along elevational gradients of the western slopes of the Ecuadorian Andes. PLOS ONE 12: e0179432.

Malavé BM, Styga JM, Clotfelter ED. 2018. Size, shape, and sex dependent variation in force production by crayfish chelae. $J$ Morphol 279: 312-318.

Mathews LM, Adams L, Anderson E, Basile M, Gottardi E, Buckholt MA 2008. Genetic and morphological evidence for substantial hidden biodiversity in a freshwater crayfish species complex. Mol Phylogenet Evol 48: 126-135.

Mazerolle MJ. 2021. Package 'AICcmodavg': Model Selection and Multimodel Inference Based on (Q)AIC(c). R Package Version 2.3.1.

McKeown AH, Schmidt RW. 2013. Geometric morphometrics. In DiGangi EA, Moore MK, eds. Research methods in human skeletal biology. Academic Press, 325-359.

Myers N, Mittermeier RA, Mittermeier CG, da Fonseca GAB, Kent J. 2000. Biodiversity hotspots for conservation priorities. Nature 403: 853-858.

Perry WL, Jacks AM, Fiorenza D, Young M, Kuhnke R, Jacquemin SJ. 2013. Effects of water velocity on the size and shape of rusty crayfish. Orconectes rusticus. Freshw Sci 32: 1398-1409. 
Previšić A, Walton C, Kučinić M, Mitrikeski P, Kerovec M. 2009. Pleistocene divergence of Dinaric Drusus endemics (Trichoptera, Limnephilidae) in multiple microrefugia within the Balkan Peninsula. Mol Ecol 18: 634-647.

R Core Team. 2021. R: A language and environment for statistical computing. R Foundation for Statistical Computing, Vienna, Austria. URL http://www.R-project.org/.

Rohlf FJ. 2015. The tps series of software. Hystrix 26: 1-4.

Rudolph E, Colihueque N, Yanez M. 2016. Morphological and genetic analysis in morphologically divergent river and lake specimens of the freshwater crayfish Samastacus spinifrons (Philippi, 1882) (Decapoda, Parastacidae). Crustaceana 89: 877-899.

Scalici M, Macale D, Gibertini G. 2010. Allometry in the ontogenesis of Austropotamobius pallipes species complex (Decapoda: Astacidae): the use of geometric morphometrics. Ital J Zool 77: 296-302.

Scalici M, Bravi R. 2012. Solving alpha-diversity by morphological markers contributes to arranging the systematic status of a crayfish species complex (Crustacea, Decapoda). J Zool Syst Evol Res 50: 89-98.

Schlager S, Jefferis G, Ian D, Schlager MS. 2021. Package 'Morpho': Calculations and Visualisations Related to Geometric Morphometrics. R Package Version 2.9.

Schrimpf A, Theissinger K, Dahlem J, et al. 2014. Phylogeography of noble crayfish (Astacus astacus) reveals multiple refugia. Freshw Biol 59: 761-776.

Schrimpf A, Piscione M, Cammaerts R, et al. 2017. Genetic characterization of Western European noble crayfish populations (Astacus astacus) for advanced conservation management strategies. Conserv Genet 18: 1299-1315.
Sint D, Dalla Via J, Füreder L. 2005. Morphological variations in Astacus astacus L. and Austropotamobius pallipes (Lereboullet) populations. Bull Fr Pêche Piscic 376-377: 637-652.

Sint D, Dalla Via J, Füreder L. 2006. The genus Austropotamobius in the Ausserfern region (Tyrol, Austria) with an overlap in the distribution of A. torrentium and A. pallipes populations. Bull Fr Pêche Piscic 380-381: 1029-1040.

Sint D, Dalla Via J, Füreder L. 2007. Phenotypical characterization of indigenous freshwater crayfish populations. J Zool 273: $210-219$.

Sommer RJ. 2020. Phenotypic plasticity: from theory and genetics to current and future challenges. Genetics 215: 1-13.

Souty-Grosset C, Reynolds JD. 2009. Current ideas on methodological approaches in European crayfish conservation and restocking procedures. Knowl Manag Aquat Ecosyst 394-395: 01.

Strayer DL, Dudgeon D. 2010. Freshwater biodiversity conservation: recent progress and future challenges. $J N$ Am Benthol Soc 29: 344-358.

Westman K, Pursiainen M, Vilkman R. 1978. A new folding trap model which prevents crayfish from escaping. Freshwater crayfish 4: $235-242$.

Wickham H. 2016. ggplot2: Elegant graphics for data analysis. Springer, $213 \mathrm{p}$.

Wilke CO, Wickham H, Wilke MCO. 2019. Package 'cowplot'. Streamlined Plot Theme and Plot Annotations for 'ggplot2'.

Zelditch ML, Swiderski DL, Sheets HD, Fink WL. 2004. Geometric morphometrics for biologists: a primer. Elsevier Academic Press, San Diego, 443 p.

Cite this article as: Lovrenčić L, Ferrón H, Grbin D, Maguire I. 2022. Insight into the noble crayfish morphological diversity: a geometric morphometric approach. Knowl. Manag. Aquat. Ecosyst., 423, 9. 